\title{
Incidence and severity of electric scooter related injuries after introduction of an urban rental programme in Vienna: a retrospective multicentre study
}

\author{
Timon Moftakhar ${ }^{1} \cdot$ Michael Wanzel $^{2}$ - Alexander Vojcsik ${ }^{3}$. Franz Kralinger ${ }^{2} \cdot$ Mehdi Mousavi $^{3} \cdot$ Stefan Hajdu $^{1}$. \\ Silke Aldrian ${ }^{1,4} \cdot$ Julia Starlinger ${ }^{1,5}$
}

Received: 24 May 2020 / Accepted: 16 August 2020 / Published online: 27 August 2020

(C) The Author(s) 2020

\begin{abstract}
Purpose Electric scooters (e-scooters) are an emerging way of mobility in cities around the world. Despite quickly rising numbers of e-scooters, limited studies report on incidence and severity of e-scooter-associated injuries. The aim of our study was to report on these injuries and identify potential protective measures to ultimately decrease e-scooter-associated morbidity.

Methods We performed a retrospective multicentre study including all patients, who were admitted to three major trauma departments in Vienna from May 2018 to September 2019. We analysed patients' data, including demographics, injury pattern, types of injury and subsequent treatment.

Results A total number of 175 patients (115 males, 60 females) sustained e-scooter-associated injuries. Patients' mean age was 34.4 years [4-74]. While the mean Injury Severity Score (ISS) was 3.4, 11 patients presented with an ISS $\geq 9$ and 2 patients with an ISS $\geq 16$. ISS increased with age. Older patients ( $\geq 40$ years) presented a significantly higher ISS than younger patients $(<40$ years) $(P=0.011)$. Seventy-one patients $(40.6 \%)$ sustained major injuries affecting head $(35.2 \%)$ and upper extremities $(36.6 \%)$. Twenty-three patients $(13.1 \%)$ required surgery leading to hospitalization of 11 days on average [1-115]. E-scooter-associated injuries increased during late afternoon plateauing at $8.00 \mathrm{pm}$. However, the largest share of patients (39.2\%) sustained their injuries during early night ( $8.00 \mathrm{pm}$ to $1.59 \mathrm{am})$ with especially young adults (19-39 years) being at risk.

Conclusion The popularity of rideshare e-scooters across cities worldwide seems to be on the rise, so are e-scooter-associated injuries. These injuries should be considered high-energy trauma affecting primarily head and upper extremity; indeed, $17.7 \%$ sustained major head injuries. Therefore, the mandatory use of a helmet seems to be adequate to decrease head injuryassociated morbidity. Ultimately, given the remarkably high rates of nighttime injuries, an e-scooter ban during night could further cut injury numbers in half.
\end{abstract}

Keywords Electric scooter $\cdot$ Scooter share $\cdot$ Trend sport $\cdot$ Injury pattern $\cdot$ Injury severity $\cdot$ Injury prevention $\cdot$ Trauma $\cdot$ Fracture $\cdot$ Head injury $\cdot$ Emergency department $\cdot$ Epidemiology $\cdot$ Retrospective study

Julia Starlinger

julia.starlinger@meduniwien.ac.at

1 Department of Orthopaedics and Trauma-Surgery, Medical University of Vienna, Vienna, Austria

2 Department of Trauma Surgery, Wilhelminenspital, Vienna, Austria

3 Department of Trauma Surgery, Sozialmedizinisches Zentrum Ost Donauspital, Vienna, Austria

4 Austrian Cluster for Tissue Regeneration, Vienna, Austria

5 Department of Orthopedic Surgery, Mayo Clinic Rochester, Rochester, MN, USA

\section{Introduction}

Across city centres worldwide, electric scooters (e-scooters) have become a popular means of transportation. In Vienna, Austria, commercial providers increased the number of available e-scooters up to about 6000 in April 2019. Doing so, the number of e-scooter-associated injuries in trauma departments across town continued to go up [1].

Recently, several authors reported on this trend [2, 3], e.g. Bekhit et al. [2] observed a striking increase of e-scooterassociated injuries in Auckland, New Zealand, from 2 up 
to 35 injuries per week after the introduction of an urban e-scooter sharing system. Namiri et al. [4] did an extensive analysis utilizing the National Electronic Injury Surveillance System reporting a significant increase of e-scooterassociated injuries in the USA from 4582 in 2014 to 14,651 in 2018.

In addition to the rising number of e-scooter-associated injuries, the severity of reported injuries is considerable, given the fact that riders on the street typically use speeds up to $20 \mathrm{miles} / \mathrm{h}$ corresponding to $32 \mathrm{~km} / \mathrm{h}$. For instance, Badeau et al. [3] report on $44 \%$ major injuries in e-scooterassociated emergency room (ER) admissions with $14 \%$ of all patients requiring surgery. Hence, e-scooter-associated injuries are beyond negligible occasionally resulting in fatal accidents.

The severity of injuries reflects the burden for the individual patient. Moreover, the injury severity together with the increasing incidence raises concerns about costs due to e-scooter-related accidents. In a study period of 7 months, e-scooter-associated injuries caused a total amount of $\$ 1.3$ million New Zealand dollars (NZD), resulting in an estimated cost of \$1300 NZD per rentable e-scooter as reported by Bekhit et al. [2]. Similarly, Campbell et al. [5] report on 23 operations which were necessary due to e-scooterassociated injuries. Doing so, the authors estimate a total economic cost of $\$ 404,925$ NZD caused by this subset of e-scooter-associated injuries.

Ridesharing e-scooters is of emerging popularity, but this trend does not come without consequences as outlined in the most recent literature. In the participating trauma departments, an increasing number of injuries due to accidents involving e-scooters have been observed. Thus, the purpose of our study was to investigate the incidence, severity and a potential injury pattern of e-scooter-associated injuries in an effort to ultimately increase user's safety, e.g. by mandatory helmet use or advanced lighting technologies [2-4, 14].

\section{Materials and methods}

We performed a retrospective multicentre study including all consecutive patients who were admitted for an e-scooterassociated injury (rider as well as non-rider) from May 1, 2018 to September 30, 2019. We therefore collected data from three of Vienna's major trauma departments: "Vienna General Hospital-Medical University of Vienna", "Sozialmedizinisches Zentrum Ost—Donauspital" and "Wilhelminenspital Wien").

The study was approved by the Institutional Review Board (IRB) (Ethics Committee of the Medical University of Vienna, No. 1804/2019) as well as the Ethics Committee of the City of Vienna (No. 19-213-VK) and conducted in accordance with the declaration of Helsinki. Due to the retrospective nature of the cohort study, no informed consent was required by the IRB. All medical records were reviewed for eligibility (e-scooter-associated injury) and data were collected by scanning patients' medical histories, outpatient documentations, surgery reports and discharge summaries (date and time of injury, age, sex, type of introduction, mechanism of injury, influence of alcohol, type of injuries, treatment, duration of hospitalization and duration of outpatient aftercare). After data collection and prior to statistical workup, patients' records were anonymized.

All injuries were classified according to the Injury Severity Score [15]. Accordingly, we categorized patients presenting with an ISS $\geq 9$ as moderately injured. Moreover, we classified all injuries into "major" (fractures, dislocations, concussions, intracranial haemorrhages) and "minor" injuries (contusions, soft tissue injuries, strains or sprains). Further, we categorized injury locations into head, upper extremities including shoulder girdle, lower extremities including pelvis and thorax including spine.

\section{Statistical analysis}

Statistical analysis was performed using SPSS 26.0 software (SPSS Inc., Chicago, IL). Comparisons between independent groups of continuous variables were performed by independent sample $t$ test and Chi-square test. The statistical significance level was set to $P \leq 0.05$.

\section{Results}

\section{A noticeable increase of e-scooter-associated injuries was observed from 2018 to 2019}

We observed a distinct increase of e-scooter-associated injuries from 2018 to 2019 resulting in a total number of 175 patients with e-scooter-associated injuries during the study period. During the overlapping 5-month summer period (May-September), we observed a considerable increase of e-scooter injuries from $2018(n=13)$ to $2019(n=116)$, representing an $892 \%$ increase (Fig. 1). Patients involved in e-scooter accidents were predominantly male $(65.7 \%)$ with a mean age of 34.4 years, ranging from 4 to 74 years. Details on patients' characteristics are shown in Table 1.

\section{E-scooter-associated injuries affected head, upper and lower extremity to the same extent}

A total of 104 patients (59.4\%) presented with minor injuries, whereas 71 patients $(40.6 \%)$ presented with major injuries: of those 71 patients with major injuries, 6 patients $(8.5 \%)$ presented with major injuries in more than one region. With respect to the anatomic location, we could 


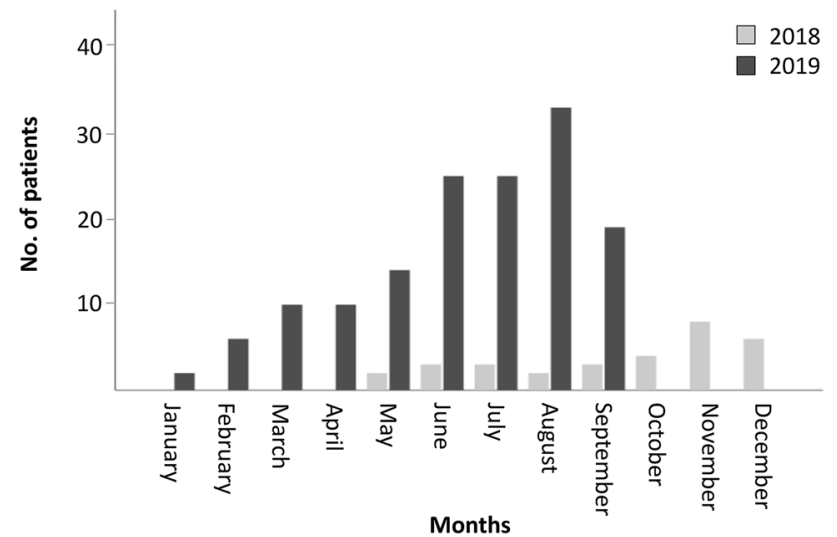

Fig. 1 Bargraph illustrating the increase of e-scooter-associated injuries in Vienna from 2018 to 2019 after the implementation of e-scooter sharing programmes

Table 1 Patients' demographics

\begin{tabular}{|c|c|}
\hline & $n(\%)$ \\
\hline Age in years (mean [range]) & $34.4[4-74]$ \\
\hline \multicolumn{2}{|l|}{ Sex } \\
\hline Male & $115(65.7)$ \\
\hline Female & $60(34.4)$ \\
\hline \multicolumn{2}{|l|}{ Mode of arrival } \\
\hline Ambulance & $60(34.3)$ \\
\hline Walk in & $99(56.6)$ \\
\hline n.a. & $16(9.1)$ \\
\hline \multicolumn{2}{|l|}{ Time of injury } \\
\hline Daytime (8.00 am to $7.59 \mathrm{pm})$ & 64 (38.6) \\
\hline Night-time (8.00 pm to $7.59 \mathrm{am})$ & $102(58.3)$ \\
\hline n.a. & $9(5.1)$ \\
\hline \multicolumn{2}{|l|}{ Treatment } \\
\hline Outpatient treatment & $125(71.4)$ \\
\hline Hospital admission & 47 (26.9) \\
\hline Not documented & $3(1.7)$ \\
\hline Length of hospital stay in days (mean [range]) & $6.5[1-115]$ \\
\hline \multicolumn{2}{|l|}{ Type of treatment } \\
\hline Non-operative management & $152(86.9)$ \\
\hline Operative management & $23(13.1)$ \\
\hline \multicolumn{2}{|l|}{ Aftercare } \\
\hline Outpatient aftercare & $59(33.7)$ \\
\hline Length of outpatient aftercare in days (mean [range]) & $38.9[1-368]$ \\
\hline \multicolumn{2}{|l|}{ Mechanism of injury } \\
\hline Rider & $166(94.9)$ \\
\hline Non-rider & $9(5.1)$ \\
\hline
\end{tabular}

not identify a typical injury pattern: 25 patients $(35.2 \%)$ sustained a major head injury, 26 patients $(36.6 \%)$ a major injury of the upper extremity, 12 patients $(16.9 \%)$ a major injury of the lower extremity, and 2 patients (2.8\%) a major

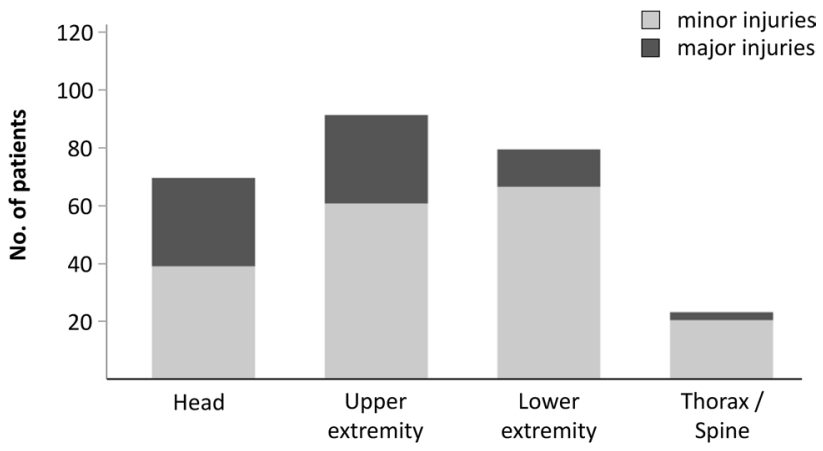

Fig. 2 Distribution of injuries in terms of anatomic location and severity

Table 2 E-scooter-associated injuries with respect to the anatomic location

\begin{tabular}{lr}
\hline & $n$ \\
\hline Head injuries (patients) & 71 \\
Fractures & 21 \\
Facial bones & 18 \\
Base of the skull & 3 \\
Intracranial haemorrhages & 7 \\
Subdural & 3 \\
Subarachnoid & 3 \\
Epidural & 1 \\
Concussions & 21 \\
Contusions of the skull & 55 \\
Fractures (non-head) (patients) & 44 \\
Upper extremities including shoulder girdle & 33 \\
Lower extremities including pelvis & 15 \\
Thorax or spine & 4 \\
Dislocations (patients) & 2 \\
Shoulder joint & 2 \\
Contusions (patients) & 82 \\
Strains or sprains (patients) & 20 \\
Soft tissue injuries (abrasions, lacerations or haematomas) & 108 \\
(patients) & \\
\hline
\end{tabular}

Categories are not mutually exclusive

injury of thorax or spine (Fig. 2). Further details on injury characteristics are listed in Table 2.

\section{The majority of e-scooter-associated injuries were managed non-operatively}

From 175 patients, 47 were admitted to the hospital. About half of them (23 patients, 14 males, 9 females) required operative management $(\mathrm{OM})$ and underwent a total of 27 surgical procedures. The average age of patients who underwent $\mathrm{OM}$ was 34.1 years [13-63]. Their ISS was significantly higher 
(6.8 [1-27]) compared to those patients who underwent non-operative management (NOM) (2.9 [1-14], $P=0.007)$. Patients treated with OM tended to have increasing length of hospital stay compared to those with NOM (OM 11.0 days [1-115], NOM 3.0 days [1-19], $P=0.177)$. Outpatient aftercare was significantly longer in patients who underwent

Table 3 Types of surgeries

\begin{tabular}{lr}
\hline & $n$ \\
\hline Osteosynthesis & 17 \\
Internal fixation with screws and/or plates & 13 \\
Percutaneous pinning & 1 \\
Tension band wiring & 1 \\
Intramedullary fixation & 2 \\
Neurosurgical interventions & 3 \\
Maxillofacial surgery & 3 \\
Ear, nose and throat (ENT) surgical procedure & 1 \\
Interventional radiological surgery & 1 \\
Soft tissue surgery & 2 \\
\hline
\end{tabular}

OM compared to patients receiving NOM (OM 105.3 days [7-368], NOM 16.3 days [1-67], $P=0.006)$. The most common surgeries were open reduction and internal fixation of fractures. Different types of surgeries performed are shown in Table 3.

\section{Severity of e-scooter-associated injuries increased with age}

We observed a noticeable trend indicating that ISS was age dependent $(P=0.001, R=0.248)$ as visualized in Fig. 3a. This difference was even more pronounced classifying patients into three age groups: adolescents ( $\leq 18$ years, $n=13$ ), young adults (19-39 years, $n=107)$ and older adults ( $\geq 40$ years, $n=55$ ). Especially patients $\geq 40$ years sustained more severe injuries, with respect to their ISS; irrespective of sex, this difference was found to be significant (ISS in all patients: < 40 years 2.9 [1-22], $\geq 40$ years 4.6 [1-27], $P=0.011$; ISS in females: $<40$ years $2.5[1-6], \geq 40$ years 3.4 [1-6], $P=0.042$; ISS in males: < 40 years 3.1 [1-22], $\geq 40$ years 5.1 [1-27], $P=0.032$; Fig. 3b).
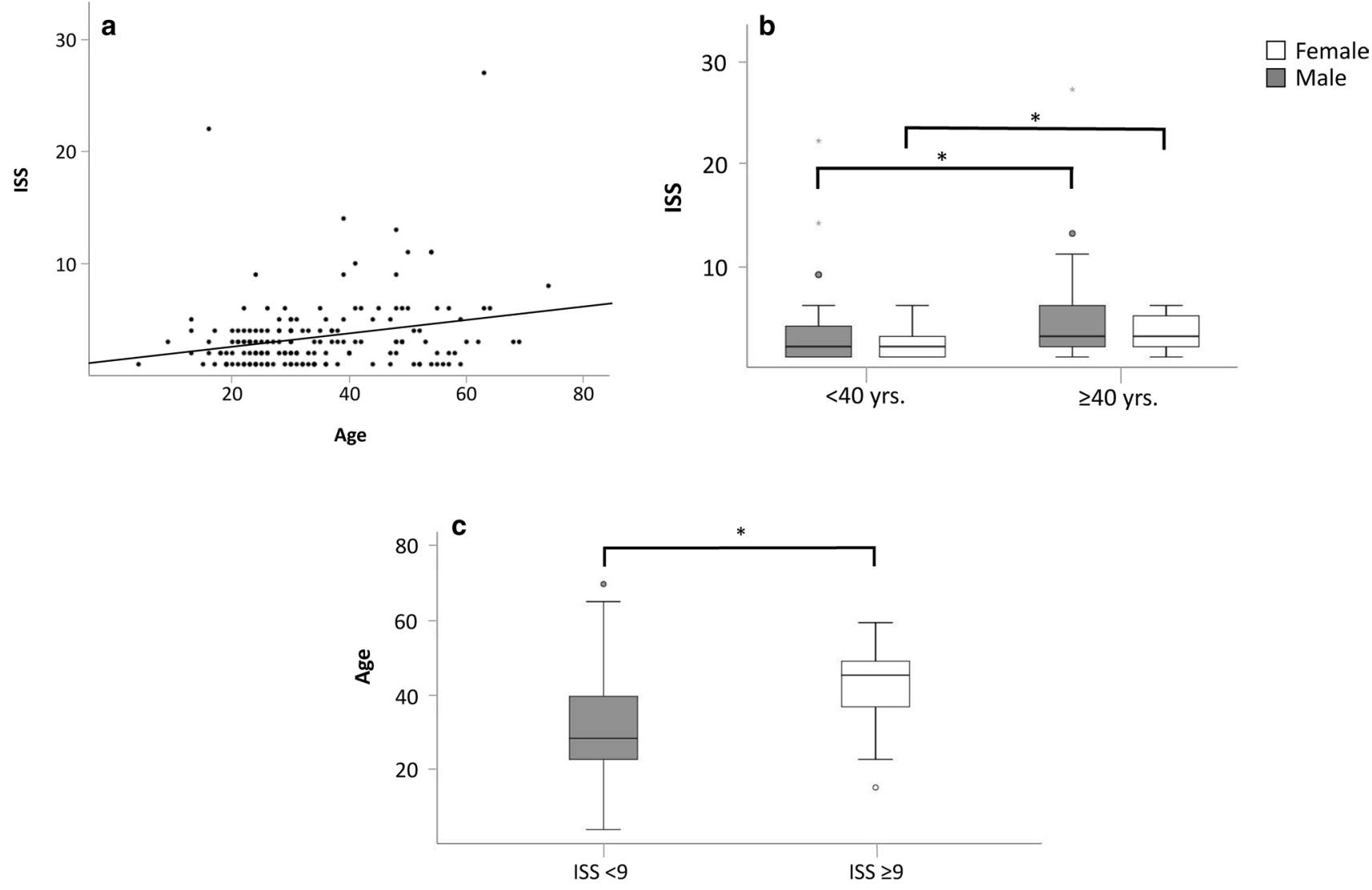

Fig. 3 a Scatterplot illustrating the significant relationship between age and ISS $(P<0.001, R=0.325)$. b Box plot showing the significantly higher ISS Scores of adults $\geq 40$ years compared to patients $<40$ years irrespective of sex. *Significant difference
$(P \leq 0.05)$. $\mathbf{c}$ Box plot showing that patients with an ISS $\geq 9$ were significantly older than patients ISS $<9(P=0.027)$. *Significant difference $(P \leq 0.05)$ 
Looking at a clinically relevant cutoff of ISS $\geq 9$, this relationship was found to be even more pronounced. Doing so, we found patients with an ISS $\geq 9$ to be significantly older than patients with an ISS $<9$ (ISS $\geq 943.3$ years [16-63], ISS $<933.8$ years [4-74], $P=0.010$; Fig. 3 c).

\section{E-scooter-associated injuries increased in the afternoon and plateaued during the night}

Eighty-two patients (49.4\%) presented during daytime (8.00 am to $7.59 \mathrm{pm})$, while 84 patients $(50.6 \%)$ sustained their injury during nighttime (8.00 pm to $7.59 \mathrm{am})$. A subgroup analysis dividing the two groups into morning and afternoon as well as early night and late night revealed a distinct increase of e-scooter-associated injuries during the afternoon plateauing at $8.00 \mathrm{pm}$. Ultimately, the largest share of patients (39.2\%) sustained the injuries during early night (8.00 pm to $1.59 \mathrm{am)} \mathrm{(Fig.} \mathrm{4a).} \mathrm{With} \mathrm{respect} \mathrm{to} \mathrm{the} \mathrm{patients'}$ age, we found older adults ( $\geq 40$ years) to be more likely to fall in the afternoon compared to young adults (19-39 years) who were at highest risk to fall during early nighttime (Fig. 4b). Out of all patients, seven patients (4.0\%) stated to have been under the influence of alcohol at the time of the injury, and all alcohol-associated injuries happened after $8 \mathrm{pm}$.

\section{Discussion}

The popularity of e-scooters is continuously increasing, so is the number of e-scooter-associated injuries. In our study, we observed a noticeable rise of e-scooter-associated ER admissions from 13 in summer 2018 (May-September) to 116 in the respective period in 2019. This corresponds to an increase of $892 \%$ of e-scooter-associated injuries in Vienna, Austria.

While the severity of injuries varied in our patients (mean ISS 3.4 [1-27]), 40.6\% sustained a major injury (fracture, dislocation, intracranial haemorrhage or concussion). Eleven patients presented with an ISS $\geq 9$ and 2 further patients with an ISS $\geq 16$. Interestingly, we found a considerable increase of ISS with age irrespective of sex. Indeed, patients presenting with an ISS $\geq 9$ were significantly older than less severely injured patients. This emphasizes the fact that e-scooter-associated injuries are beyond benign and should be considered as high-energy trauma injuries with potentially life-threatening extent.

With respect to the anatomic area, we found the highest number of e-scooter-associated injuries for the upper extremity $(53.1 \%)$. As similar trend sports (e.g. riding a micro-scooter or roller-skating) typically cause fractures of the wrist region, the authors usually recommended wrist protectors for the prevention of these distinct injury patterns $[6,7]$; so did Ishmael et al. [8] by reporting on e-scooterassociated injuries requiring surgery, as 11 out of 75 patients sustained wrist fractures. Interestingly, we did not find a typical injury pattern for e-scooter-associated injuries affecting the wrist. Indeed, elbow fractures were more likely than wrist fractures (11 versus 3 ) in our patients. While Ishmael et al. [8] recommended the use of wrist guards for e-scooter riders, based on our numbers, the overall benefit might be only marginal.

The use of protective gear is worthwhile considering, given the high number of head injuries observed in our patients: we found the head to be at major risk for e-scooterassociated injuries, as $40.6 \%$ of the patients sustained an injury in this region with $43.7 \%$ sustaining a major head injury. These findings go in line with the report by Trivedi
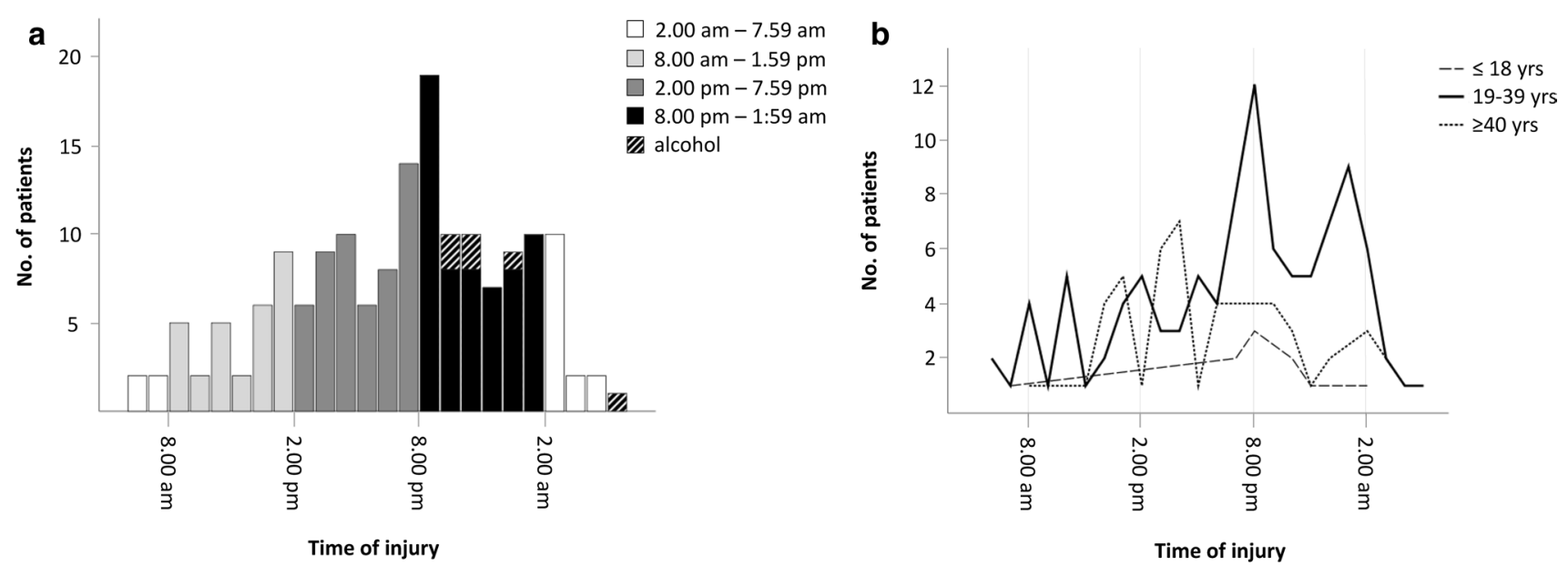

Fig. 4 a Distribution of the rate of injuries in respect of the time of injury. b Line chart illustrating the different rates of injuries of the three classified age groups (adolescents, young adults and older adults) over the course of the day 
et al., who had observed $40.2 \%$ head injuries studying 249 e-scooter-associated injuries [9].

At the same time, the city of Brisbane passed a law for compulsory helmet use for e-scooter riders in January 2019. Interestingly, Mitchell et al. studied the incidence of e-scooter-associated injuries in Brisbane from November 2018 to January 2019, covering the time when the use of helmets became mandatory. Doing so, the related effect was considerable as the authors observed a subsequent helmet use in $46 \%$ of their patients. The authors further concluded that the use of a helmet at the time of injury significantly decreased the risk of sustaining a head injury compared to patients not wearing a helmet [10]. This goes in line with reports studying the protective potential of helmets in other road users. Olivier et al. [11] presented similar findings reporting that helmet use while riding a bicycle is associated with a significant reduction of head injuries, corresponding to an odds ratio of 0.49 by the use of a helmet. Namiri et al. reported more than one-third of all e-scooter-associated injuries affecting the head region, leading to more than double the rate of head injuries, related to bicycle injuries [4, 12].

Currently available data on head injuries in e-scooter riders report heterogeneous numbers being as high as up to $40.2 \%[3,9,13]$. Unlike in Brisbane, Australia, the use of a helmet is not mandatory for riding an e-scooter in any European capital. To this end, a law for compulsory use of helmet for e-scooter riders could lead to a significant reduction of e-scooter-associated head injuries and seems of utmost importance.

Several authors have already reported increased numbers of ER admissions during the evening and nighttime [9, 14]. Doing so, Trivedi et al. [9] reported that $56.6 \%$ of e-scooterassociated injuries occurred between $3.00 \mathrm{pm}$ and $11.00 \mathrm{pm}$. Similarly, Blomberg [14] found that 68 patients (52.3\%) sustained their injury between $3.00 \mathrm{pm}$ and $11.00 \mathrm{pm}$ and 38 patients (29.2\%) were injured between $11.00 \mathrm{pm}$ and 7.00 am. Our results are in line with the above-mentioned observations, as we also observed a continuous increase in the evening with a peak around $8.00 \mathrm{pm}$. However, most of the injuries in our study occurred during night $(8.00 \mathrm{pm}$ to 7.59 am) affecting primarily young adults. Given this pronounced peak during the night, an e-scooter ban at night might substantially decrease the number of injuries and should therefore be taken into account. Alternatively, advanced built-in lighting technologies to enhance the visibility of e-scooter riders could lead to a reduction of e-scooter-associated accidents during nighttime.

Moreover, seven patients self-reported to be riding the e-scooter under the influence of alcohol at the time of the injury. All seven patients sustained major head injuries, including one patient with an additional major injury of the upper extremity. Thus, e-scooter riders under the influence of alcohol had a significantly higher risk of sustaining major injuries $(P=0.001)$. Given the fact that these seven patients were injured during the nighttime, a possible night ban for e-scooters could likewise reduce the number of injuries sustained under the influence of alcohol.

\section{Conclusion}

Given the rising numbers of e-scooter-associated injuries seen in trauma departments across Vienna, this study aims to report on the severity and injury pattern of this new means of transportation. In addition to the currently available literature, we report on a high number of patients sustaining head injuries $[3,4,9,13]$. Thus, the mandatory use of a helmet seems an adequate measure to prevent these injuries in the future. Moreover, banning the use of e-scooters during the overnight hours should be evaluated as more than $50 \%$ of e-scooter-associated injuries happened during nighttime in our patients as well as in several other reports $[9,14]$. To this end, e-scooter riders are the least protected road users, therefore it is necessary to implement extended safety precautions.

Acknowledgments Open access funding provided by Medical University of Vienna.

\section{Compliance with ethical standards}

Conflict of interest The authors declare that they have no conflict of interest.

Open Access This article is licensed under a Creative Commons Attribution 4.0 International License, which permits use, sharing, adaptation, distribution and reproduction in any medium or format, as long as you give appropriate credit to the original author(s) and the source, provide a link to the Creative Commons licence, and indicate if changes were made. The images or other third party material in this article are included in the article's Creative Commons licence, unless indicated otherwise in a credit line to the material. If material is not included in the article's Creative Commons licence and your intended use is not permitted by statutory regulation or exceeds the permitted use, you will need to obtain permission directly from the copyright holder. To view a copy of this licence, visit http://creativecommons.org/licenses/by/4.0/.

\section{References}

1. Rachbauer S (2019) E-Scooter-Boom ohne Ende: Erste Rufe nach Obergrenzen. Telekurier Online Medien GmbH \& Co KG. https ://kurier.at/chronik/oesterreich/e-scooter-boom-ohne-ende-erste -rufe-nach-obergrenzen/400469119. Accessed 26 Mar 2020

2. Bekhit MNZ, Le Fevre J, Bergin CJ (2020) Regional healthcare costs and burden of injury associated with electric scooters. Injury 51(2):271-277. https://doi.org/10.1016/j.injury.2019.10.026

3. Badeau A, Carman C, Newman M, Steenblik J, Carlson M, Madsen T (2019) Emergency department visits for electric scooterrelated injuries after introduction of an urban rental program. 
Am J Emerg Med 37(8):1531-1533. https://doi.org/10.1016/j. ajem.2019.05.003

4. Namiri NK, Lui H, Tangney T, Allen IE, Cohen AJ, Breyer BN (2020) Electric scooter injuries and hospital admissions in the United States, 2014-2018. JAMA Surg. https://doi.org/10.1001/ jamasurg.2019.5423

5. Campbell A, Wong N, Monk P, Munro J, Bahho Z (2019) The cost of electric-scooter related orthopaedic surgery. N Z Med J 132(1501):57-63

6. Schieber RA, Branche-Dorsey CM, Ryan GW, Rutherford GW Jr, Stevens JA, O'Neil J (1996) Risk factors for injuries from inline skating and the effectiveness of safety gear. N Engl J Med 335(22):1630-1635. https://doi.org/10.1056/nejm19961128335 2202

7. Zalavras C, Nikolopoulou G, Essin D, Manjra N, Zionts LE (2005) Pediatric fractures during skateboarding, roller skating, and scooter riding. Am J Sports Med 33(4):568-573. https://doi. org/10.1177/0363546504269256

8. Ishmael CR, Hsiue PP, Zoller SD, Wang P, Hori KR, Gatto JD, Li R, Jeffcoat DM, Johnson EE, Bernthal NM (2020) An early look at operative orthopaedic injuries associated with electric scooter accidents: bringing high-energy trauma to a wider audience. J Bone Joint Surg Am 102(5):e18. https://doi.org/10.2106/ jbjs. 19.00390

9. Trivedi TK, Liu C, Antonio ALM, Wheaton N, Kreger V, Yap A, Schriger D, Elmore JG (2019) Injuries associated with standing electric scooter use. JAMA Netw Open 2(1):e187381. https://doi. org/10.1001/jamanetworkopen.2018.7381

10. Mitchell G, Tsao H, Randell T, Marks J, Mackay P (2019) Impact of electric scooters to a tertiary emergency department: 8-week review after implementation of a scooter share scheme. Emerg Med Australas 31(6):930-934. https://doi. org/10.1111/1742-6723.13356

11. Olivier J, Creighton P (2017) Bicycle injuries and helmet use: a systematic review and meta-analysis. Int J Epidemiol 46(1):278292. https://doi.org/10.1093/ije/dyw153

12. Sanford T, McCulloch CE, Callcut RA, Carroll PR, Breyer BN (2015) Bicycle trauma injuries and hospital admissions in the United States, 1998-2013. JAMA 314(9):947-949. https://doi. org/10.1001/jama.2015.8295

13. Beck S, Barker L, Chan A, Stanbridge S (2020) Emergency department impact following the introduction of an electric scooter sharing service. Emerg Med Australas 32(3):409-415. https://doi.org/10.1111/1742-6723.13419

14. Blomberg SNF, Rosenkrantz OCM, Lippert F, Collatz Christensen H (2019) Injury from electric scooters in Copenhagen: a retrospective cohort study. BMJ Open 9(12):e033988. https://doi. org/10.1136/bmjopen-2019-033988

15. Baker SP, O'Neill B, Haddon W Jr, Long WB (1974) The injury severity score: a method for describing patients with multiple injuries and evaluating emergency care. J Trauma 14(3):187-196

Publisher's Note Springer Nature remains neutral with regard to jurisdictional claims in published maps and institutional affiliations. 